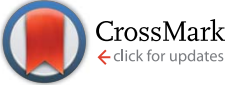

Cite this: Chem. Sci., 2016, 7, 6946

\title{
Square channels formed by a peptide derived from transthyretin $\dagger$
}

\author{
Stan Yoo, Adam G. Kreutzer, Nicholas L. Truex and James S. Nowick* \\ High-resolution structures of peptide supramolecular assemblies are key to understanding amyloid \\ diseases and designing peptide-based materials. This paper explores the supramolecular assembly of \\ a macrocyclic $\beta$-sheet peptide derived from transthyretin (TTR). The peptide mimics the $\beta$-hairpin \\ formed by the $\beta$-strands $G$ and $H$ of TTR, which form the interface of the TTR tetramer. X-ray \\ crystallography reveals that the peptide does not form a tetramer, but rather assembles to form square \\ channels. The square channels are formed by extended networks of $\beta$-sheets and pack in a "tilted \\ windows" pattern. This unexpected structure represents an emergent property of the peptide and \\ broadens the scope of known supramolecular assemblies of $\beta$-sheets.
}

Received 3rd May 2016

Accepted 28th July 2016

DOI: $10.1039 / c 6 s c 01927 g$

www.rsc.org/chemicalscience

come together in an edge-to-edge fashion to form dimers. The dimers further pack in a face-to-face fashion to form tetramers (Fig. 1). ${ }^{15}$ The TTR tetramers transport thyroid hormone and retinol-binding protein. Dissociation of the tetramers into monomers leads to formation of insoluble fibrils and toxic oligomers, which are associated with TTR-related amyloid diseases. ${ }^{16}$ Kelly and coworkers have invented an innovative approach for treating familial amyloid polyneuropathy by stabilizing the tetramers with a small molecule drug called tafamidis. ${ }^{17}$ Tafamidis acts by binding to the dimerization interface of two dimers and preventing dissociation into monomers.

Inspired by the importance of the dimerization interface in stabilizing the TTR assembly and the propensity of TTR to form fibrils, we set out to elucidate the assembly of the $\beta$-hairpin that comprises the dimerization interface of the TTR tetramer. ${ }^{19} \mathrm{We}$ incorporated the two $\beta$-strands from the TTR $\beta$-hairpin into a macrocyclic $\beta$-sheet and studied its assembly by X-ray crystallography. To our surprise, we discovered that the peptide exhibits a new mode of supramolecular assembly, forming square channels consisting of an extended network of $\beta$-sheets.

\section{Results}

Design, synthesis, and structure determination of peptide 1

We incorporated residues 106-112 from strand G of TTR and residues $115-121$ from strand $\mathrm{H}$ into a macrocyclic $\beta$-sheet (Fig. 2). We used two $\delta$-linked ornithine ( $\left.{ }^{\delta} \mathrm{Orn}\right)$ turn units to connect these two $\beta$-strands and form a macrocycle. ${ }^{20}$ We replaced the proline-tyrosine turn (residues 113 and 114) with a ${ }^{\delta}$ Orn turn to promote $\beta$-hairpin formation. We connected residues 106 and 121 with another ${ }^{\delta}$ Orn turn to reinforce the $\beta$ hairpin structure. ${ }^{21,22}$ We also incorporated an $N$-methyl group on alanine $109 \quad\left(\mathrm{~N}-\mathrm{Me}_{\mathrm{A}} \mathrm{A}_{109}\right)$ to prevent uncontrolled

Department of Chemistry, University of California, Irvine, California 92697-2025, USA.E-mail: jsnowick@uci.edu

$\dagger$ Electronic supplementary information (ESI) available. See DOI: 10.1039/c6sc01927g 

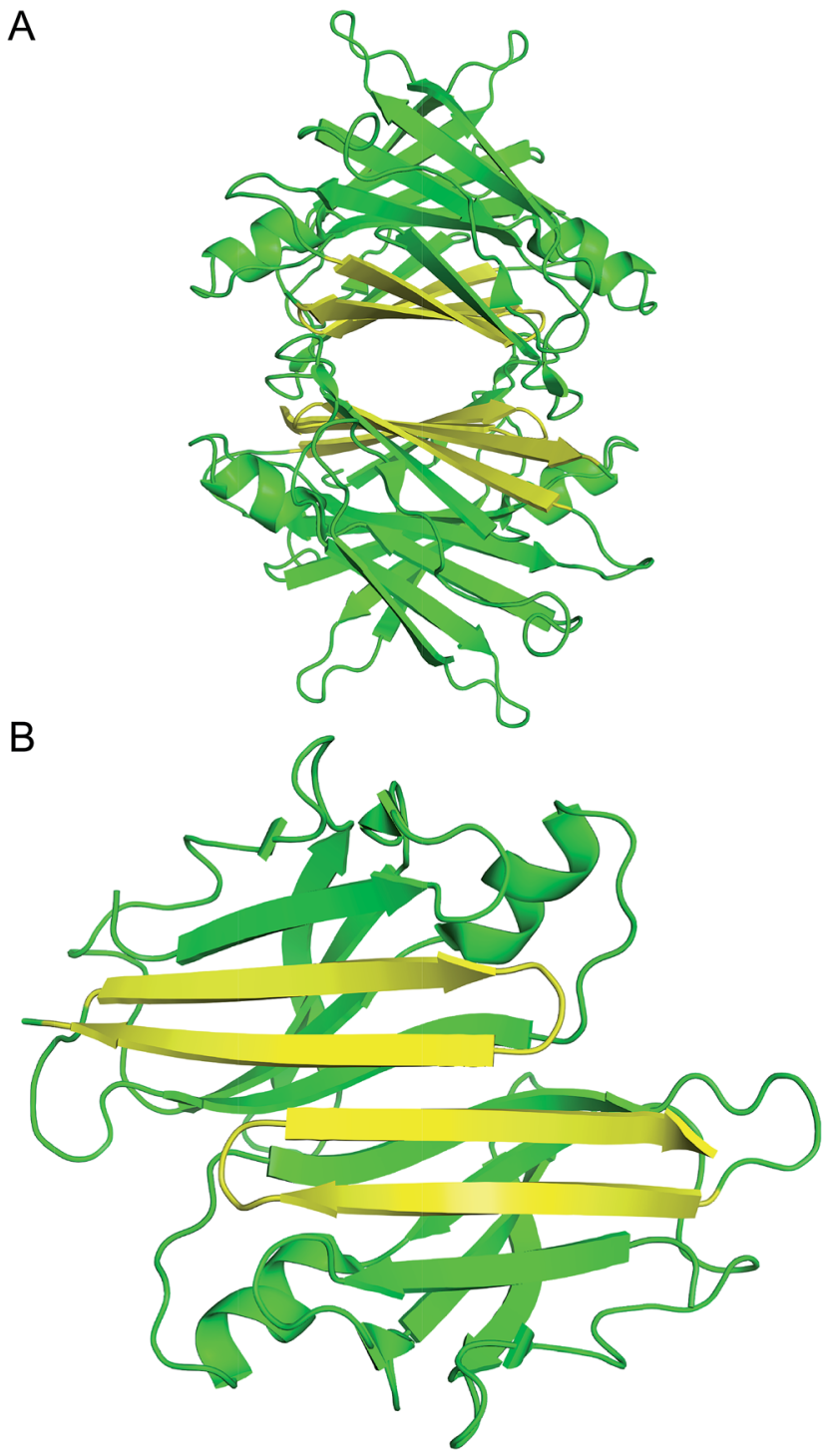

Fig. 1 (A) X-ray crystallographic structure of the TTR tetramer. The $\beta$ hairpin of the tetramer interface is highlighted in yellow (PDB 1DVQ). ${ }^{18}$ (B) TTR dimer subunit.

aggregation. ${ }^{23,24}$ We replaced tyrosine 116 with $p$-iodo-phenylalanine $\left(\mathrm{F}_{116}^{\mathrm{I}}\right)$ to determine the X-ray crystallographic phases by single-wavelength anomalous diffraction (SAD) phasing. ${ }^{25}$

Peptide 1 was synthesized as the trifluoroacetic acid (TFA) salt using standard Fmoc-based solid-phase peptide synthesis, solution-phase cyclization, and RP-HPLC purification. The TFA salt is readily soluble in water, but crystallizes or aggregates in buffer, depending on the conditions. ${ }^{26}$ Peptide 1 was screened in 288 crystallization conditions using Hampton Research crystallization kits (Crystal Screen, Index, and PEG/Ion). Peptide 1 grew rod-shaped crystals suitable for X-ray diffraction after two weeks in $0.1 \mathrm{M} \mathrm{NaOAc}$ buffer at pH 5.3, $0.2 \mathrm{M} \mathrm{CaCl}_{2}$, and $31 \%$ isopropanol. X-ray diffraction data were collected to $2.08 \AA$ using an X-ray diffractometer with a $\mathrm{Cu}$ rotating anode. The Xray crystallographic structure of peptide 1 was solved and

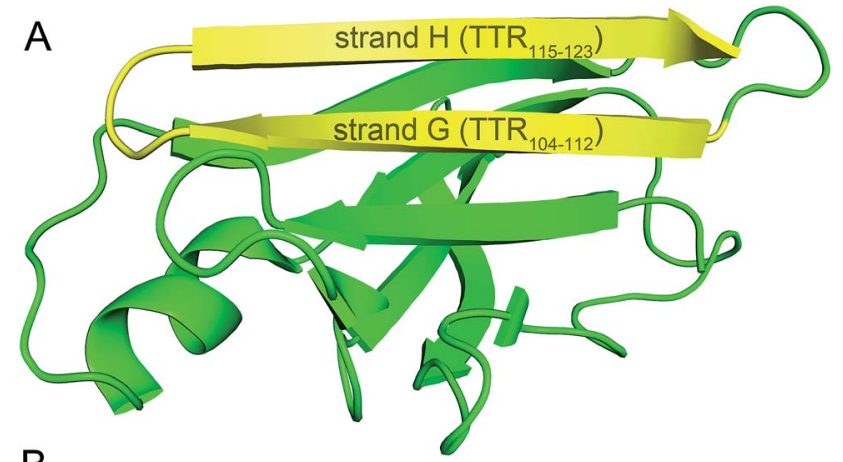

B

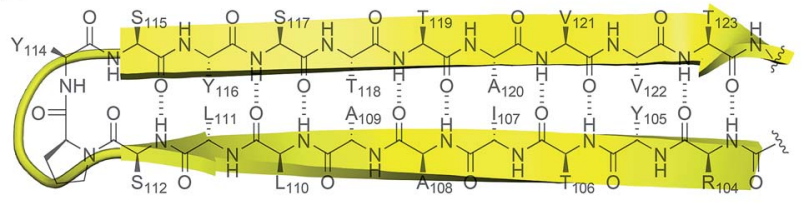

$$
\begin{aligned}
& \text { C }
\end{aligned}
$$

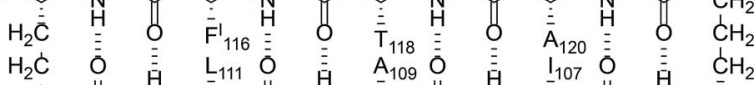

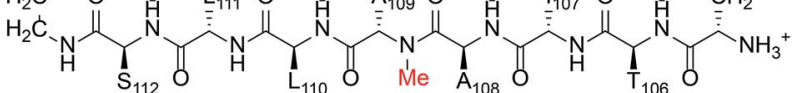

Fig. 2 (A) TTR monomer. The $\beta$-hairpin comprising $\beta$-strands $G$ and $H$ is highlighted in yellow. (B) Cartoon and chemical structure of the $\beta$ hairpin comprising $\beta$-strands $G$ and $H$. (C) Chemical structure of peptide 1.

refined in the $P 4_{3} 2_{1} 2$ space group, with one macrocycle in the asymmetric unit.

\section{X-ray crystallography of peptide 1}

The X-ray crystallographic structure of peptide 1 reveals a hierarchical supramolecular assembly. The peptide folds to form a $\beta$-hairpin monomer. The $\beta$-hairpin assembles to form extended $\beta$-sheets. Four extended $\beta$-sheets form a square channel. The square channels pack into a pattern that resembles tilted windows.

及-Hairpin monomer. Peptide 1 forms a hydrogen-bonded antiparallel $\beta$-sheet (Fig. 3). The $\beta$-sheet is relatively flat, with two distinct surfaces. One surface displays side chains from residues $\mathrm{T}_{106}, \mathrm{~A}_{108}, \mathrm{~L}_{110}, \mathrm{~S}_{112}, \mathrm{~S}_{115}, \mathrm{~S}_{117}, \mathrm{~T}_{119}$, and $\mathrm{V}_{121}$; the other surface displays side chains from $\mathrm{I}_{107}, N-M e-\mathrm{A}_{109}, \mathrm{~L}_{111}$, $\mathrm{F}_{116}^{\mathrm{I}}, \mathrm{T}_{118}$, and $\mathrm{A}_{120}$. We term these two surfaces the major and minor faces. The major face contains mostly polar side chains and the minor face contains mostly hydrophobic side chains.

Extended $\boldsymbol{\beta}$-sheets. Peptide $\mathbf{1}$ forms an extended network of $\beta$-sheets (Fig. 4). The $\beta$-sheets are not fully aligned, but rather are shifted by four residues toward the C-terminus. The upper strand of one $\beta$-hairpin monomer forms four hydrogen bonds with the lower strand of the adjacent $\beta$-hairpin monomer. The $\delta$ $\mathrm{NH}$ of the ornithine that connects $\mathrm{S}_{112}$ and $\mathrm{S}_{115}$ hydrogen bonds with the amide oxygen of $\mathrm{T}_{118}$; the amide oxygen of $\mathrm{A}_{112}$ hydrogen bonds with the $\alpha-\mathrm{NH}$ of $\mathrm{T}_{119}$; the $\alpha-\mathrm{NH}$ of $\mathrm{L}_{111}$ 
A

B
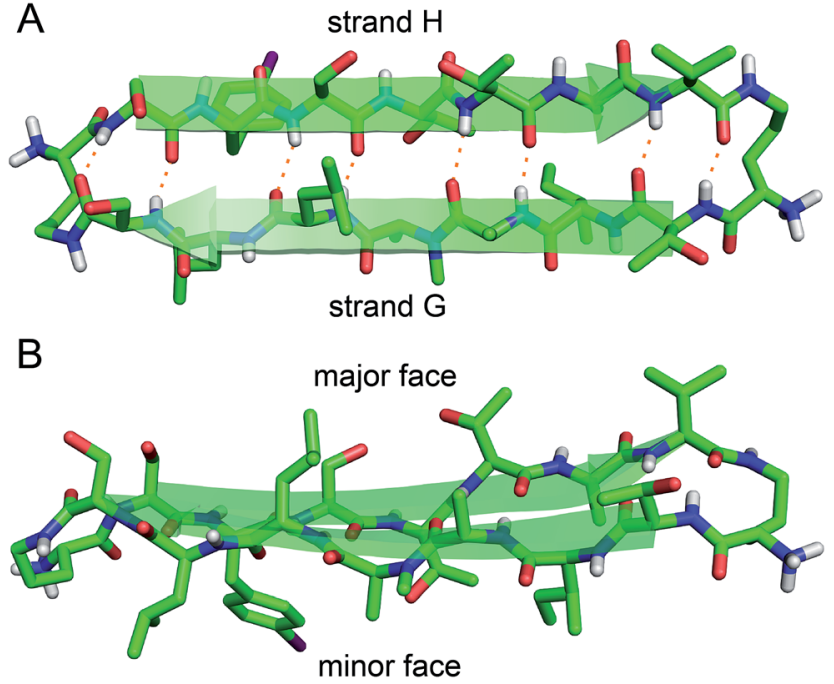

Fig. 3 X-ray crystallographic structure of peptide 1 (PDB 5HPP). (A) Hydrogen-bonded $\beta$-hairpin monomer. (B) Side view of the $\beta$-hairpin monomer.
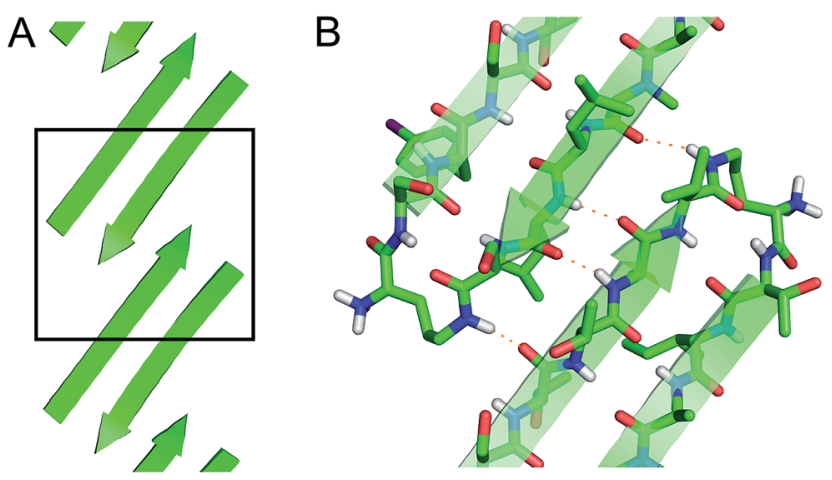

Fig. 4 (A) Extended $\beta$-sheet formed by peptide 1. (B) Detail showing hydrogen-bonding interactions between $\beta$-sheets.

hydrogen bonds with the amide oxygen of $\mathrm{A}_{120}$; the amide oxygen of $N$-Me- $\mathrm{A}_{110}$ hydrogen bonds with the $\delta$-NH of the ornithine that connects $\mathrm{T}_{106}$ and $\mathrm{V}_{121}$.

Square channels. Four extended $\beta$-sheets make the sides of a square channel (Fig. 5). Each side of the square channel is approximately $22 \AA$ long, and the inside of the channel is hollow. The side chains of $\mathrm{I}_{107}, N-\mathrm{Me}-\mathrm{A}_{109}, \mathrm{~L}_{111}, \mathrm{~F}_{116}^{\mathrm{I}}$, and $\mathrm{A}_{120}$ point into the square channel, creating a hydrophobic interior. The side chains of $\mathrm{T}_{106}, \mathrm{~S}_{112}, \mathrm{~S}_{115}, \mathrm{~S}_{117}$, and $\mathrm{T}_{119}$ point outward, making the outer surface of the square channel mostly polar. Fig. 5B shows a top view of the square channel and illustrates the hydrophobic interior and the polar outer surface.

Each square channel is stabilized by extended networks of hydrogen bonds between the four sides. The upper strand of each $\beta$-hairpin monomer in one side forms four hydrogen bonds with the lower strand of each $\beta$-hairpin monomer in the adjacent side (Fig. 5C and D). The amide oxygen of $\mathrm{A}_{108}$ hydrogen bonds with the $\alpha$-NH of the ornithine that connects $\mathrm{S}_{112}$ and $\mathrm{S}_{115}$; the $\alpha$-NH of $\mathrm{I}_{107}$ hydrogen bonds with the amide
A

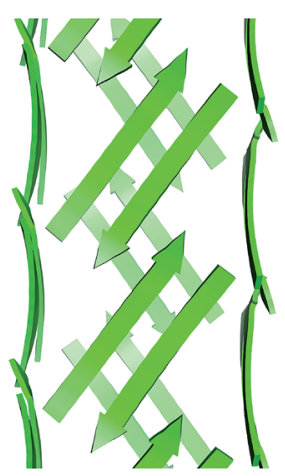

B

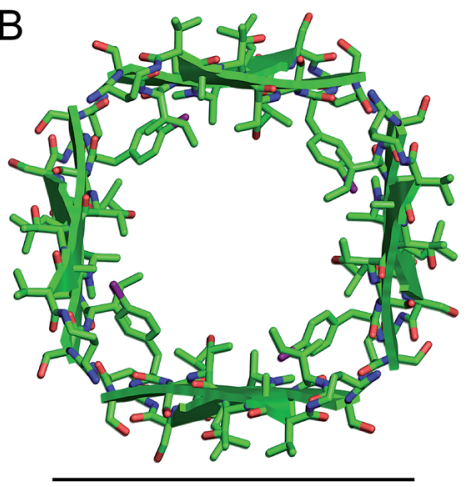

$22 \AA$
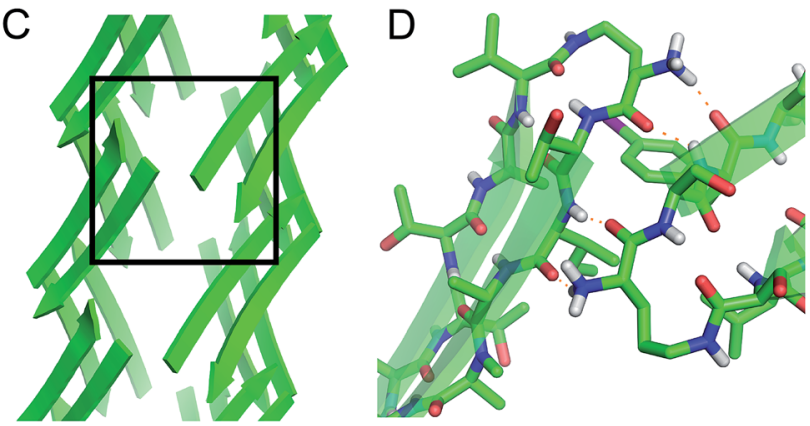

Fig. 5 Square channel formed by peptide 1. (A) Side view. (B) Top view. (C) Corner view. (D) Detail showing hydrogen-bonding interactions between $\beta$-sheets at the corner of the square channel.

oxygen of $\mathrm{S}_{115}$; the amide oxygen of $\mathrm{T}_{106}$ hydrogen bonds with the $\alpha-\mathrm{NH}$ of $\mathrm{F}_{116}^{\mathrm{I}}$; the $\alpha$-NH of the ornithine that connects $\mathrm{T}_{106}$ and $\mathrm{V}_{121}$ hydrogen bonds with the amide oxygen of $\mathrm{S}_{117}$.

These two networks of hydrogen bonds-those within the extended $\beta$-sheets (Fig. 4) and those between the extended $\beta$ sheets (Fig. 5C and D)-stabilize the square channels. All of the amide $\mathrm{NH}$ and carbonyl groups participate in hydrogen bonding, except the $\alpha$-NH of $\mathrm{T}_{118}$. To visualize how these two hydrogen-bonding networks act together to stabilize the square channels, one can imagine breaking all of the hydrogen bonds between two extended $\beta$-sheets at the corner of the square channel and unrolling and flattening the square channel (Fig. 6).

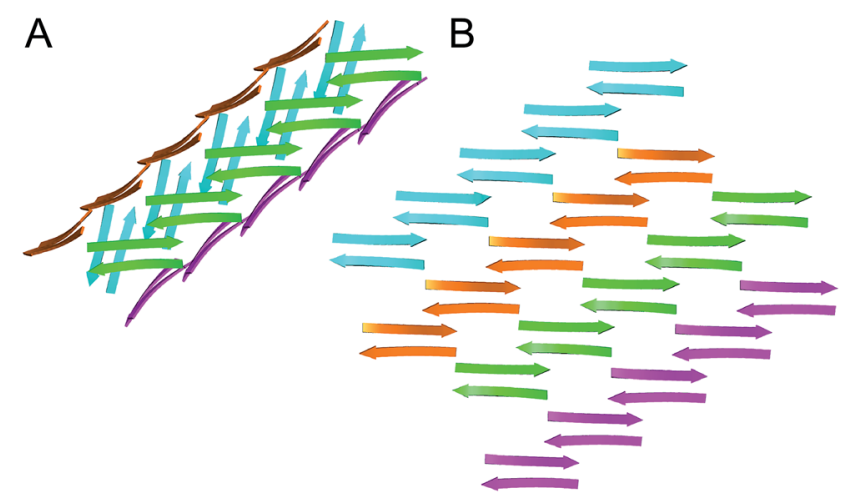

Fig. 6 (A) Square channel. (B) Square channel unrolled and flattened. 
A

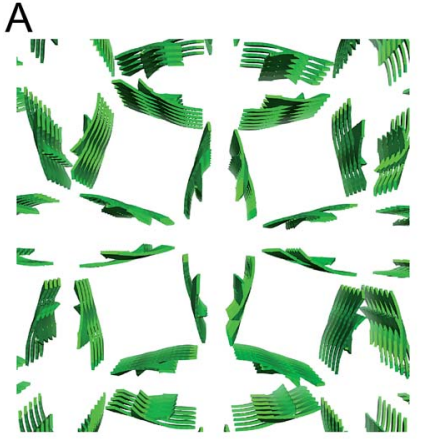

C

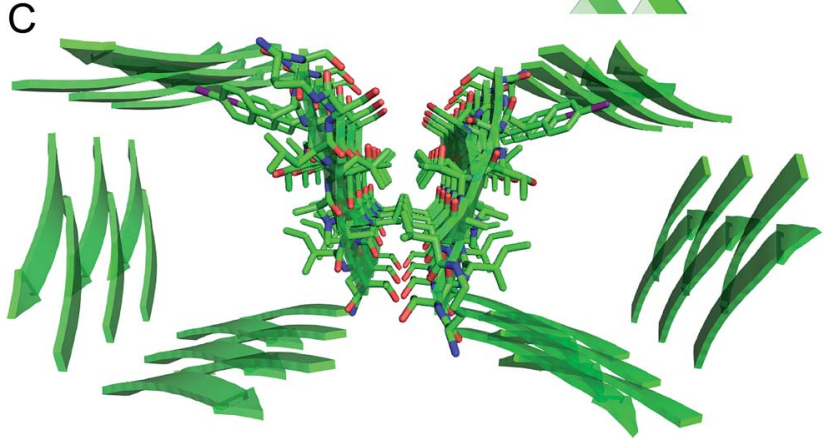

Fig. 7 (A) Tilted windows assembly of square channels. (B) Side view of the interface between two square channels. (C) Hydrophobic contact between two square channels.

Tilted windows. The square channels further assemble in a "tilted windows" pattern (Fig. 7). The square channels do not align perfectly in the crystal lattice, but rather are tilted. Each channel makes limited hydrophobic contact with the neighboring channel. Although the outer surface is composed mostly of solvated polar side chains that are not in direct contact, hydrophobic contacts between $\mathrm{V}_{121}$ on adjacent square channels stabilize the tilted windows packing.

\section{Discussion}

In designing peptide $\mathbf{1}$ to mimic the TTR tetramerization interface, we anticipated that a tetramer would form (Fig. 8A). Instead of recapitulating the natural mode of assembly of TTR, peptide 1 forms a new mode of supramolecular assembly that has not been observed previously by X-ray crystallographysquare channels. In the dimer subunit of the native TTR tetramer, strand $\mathrm{H}$ of one monomer pairs with strand $\mathrm{H}$ of another monomer. In the extended $\beta$-sheet formed by peptide $\mathbf{1}$, strand $\mathrm{H}$ pairs with strand G (Fig. 8B). The $\beta$-hairpins are shifted by two residues toward the $\mathrm{N}$-terminus in the native TTR, while the $\beta$-hairpins in peptide $\mathbf{1}$ are shifted by four residues toward the C-terminus. The differences of the two assemblies may arise because other interactions, in addition to the $\beta$-sheet interactions, also stabilize the native TTR tetramer.

The square channels formed by peptide 1 resemble $\beta$-barrels, because both are tubular structures that are composed of networks of hydrogen-bonded $\beta$-strands. Eisenberg and coworkers found that an amyloidogenic peptide from $\alpha \mathrm{B}$
A

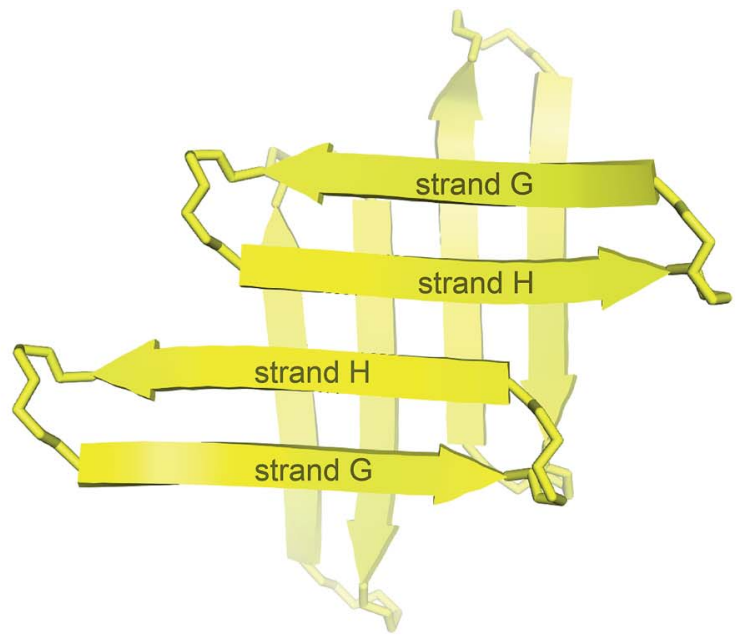

B
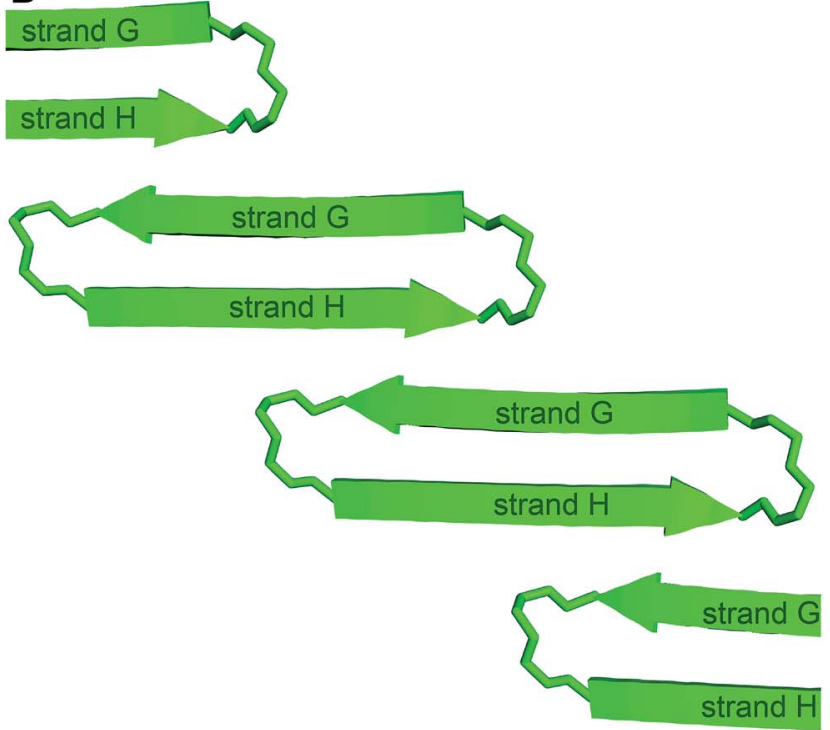

Fig. 8 (A) Hypothesized tetramer of peptide 1. (B) Crystallographically observed extended $\beta$-sheet formed by peptide 1 .

crystallin forms a six-stranded $\beta$-barrel, which they termed a "cylindrin" (Fig. 9). ${ }^{6}$ The square channels formed by peptide 1 resemble the cylindrin in that the interior is hydrophobic. The
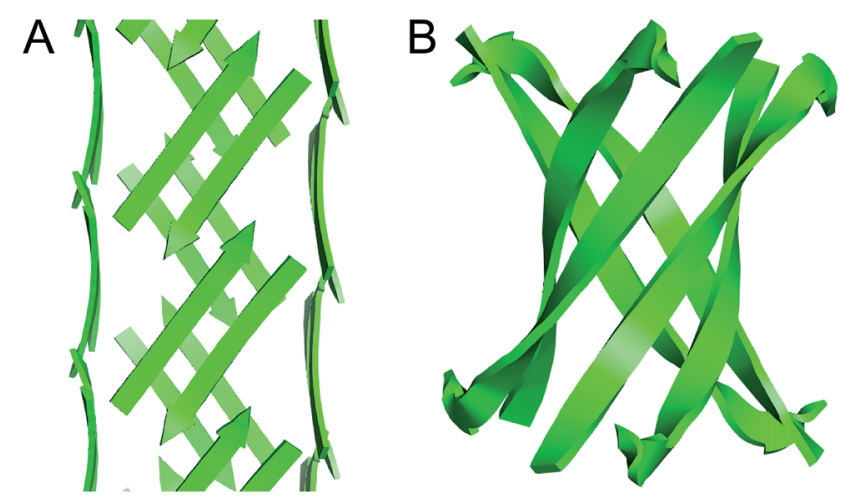

Fig. 9 (A) Square channel formed by peptide 1. (B) Cylindrin formed by a peptide fragment from $\alpha$ B crystallin (PDB 3SGO). 
structures differ in that the square channels are hollow and run the length of the crystal, while the cylindrin forms a discrete hexamer with a tightly packed interior.

The interfaces between the square channels formed by peptide 1 resemble the layered $\beta$-sheet structures that compose amyloid fibrils. In amyloid fibrils, adjacent $\beta$-sheets form laminated layers in which the $\beta$-strands are nearly orthogonal to the fibril axis. The interfaces formed by the square channels in the "tilted windows" pattern are not as tightly laminated as many amyloid interfaces, such as the "steric zippers" discovered by Eisenberg and coworkers (Fig. 10). ${ }^{2}$ The $\beta$-strands of the square channels are not orthogonal to the channel axis, but rather are at about a $40^{\circ}$ angle.

Developing new peptide supramolecular assemblies enhances the understanding of peptide and protein interactions and also facilitates the creation of new molecular devices and functional materials. ${ }^{27-31}$ The supramolecular assemblies formed by peptide $\mathbf{1}$ are particularly reminiscent of a few important peptide nanostructures formed by $\beta$-sheets. Ghadiri and coworkers designed cyclic peptides that form hollow nanotubes in the solid state and in lipid bilayer membranes. ${ }^{32,33}$ The peptides are composed of alternating $\mathrm{D}^{-}$and L-amino acids and assemble to form extended $\beta$-sheet-like structures. Lynn and coworkers found that peptide fragments from the central region of $A \beta, A \beta_{16-22}$, assemble to form large nanotubes composed of $\beta$-sheets. ${ }^{34,35}$ Schneider and coworkers developed peptide hydrogels as drug delivery vehicles. ${ }^{36-38}$ The hydrogels are composed of $\beta$-hairpin peptides with alternating hydrophobic and polar residues.

Although we do not yet understand all of the rules governing the supramolecular assembly of $\beta$-sheets, it is clear that the hydrogen-bonding edges impart Lego-like assembly. ${ }^{39}$ What makes the square channels formed by macrocyclic $\beta$-sheet peptide 1 especially interesting is that we did not design the peptide to assemble in this fashion, but rather this mode of assembly emerged from the structure and sequence of the peptide. The incorporation of a single $N$-methyl group helps reduce the near-infinite ways in which a pre-organized $\beta$-sheet can assemble and allows a single mode of self-assembly to emerge. As we continue to study the supramolecular assembly of $\beta$-sheet peptides containing different amino acid sequences, we anticipate better understanding how the structure and
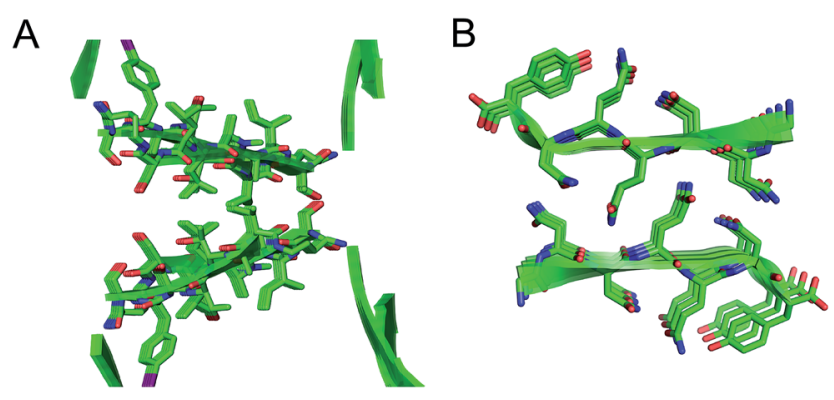

Fig. 10 (A) Interface between square channels in the tilted windows assembly. (B) Steric zipper formed by a peptide from the yeast prion protein Sup35 (PDB 1YJP). sequence of a peptide dictates its mode of supramolecular assembly.

\section{Conclusion}

In our efforts to explore the supramolecular assembly of $\beta$ sheets, we have designed a macrocyclic peptide derived from TTR. Rather than recapitulating the assembly of the native TTR tetramer, the peptide formed square channels that comprise extended networks of hydrogen-bonded $\beta$-sheets. This unanticipated result is intriguing, because the assembly represents an emergent property of the peptide. We anticipate that this new assembly of $\beta$-sheets will serve as a piece of puzzle toward understanding the rules of $\beta$-sheet supramolecular assembly.

\section{Acknowledgements}

This work was supported by the National Science Foundation (NSF CHE-1507840).

\section{Notes and references}

1 A. T. Petkova, Y. Ishii, J. J. Balbach, O. N. Antzutkin, R. D. Leapman, F. Delaglio and R. Tycko, Proc. Natl. Acad. Sci. U. S. A., 2002, 99, 16742-16747.

2 R. Nelson, M. R. Sawaya, M. Balbirnie, A. O. Madsen, C. Riekel, R. Grothe and D. Eisenberg, Nature, 2005, 435, 773-778.

3 T. Luhrs, C. Ritter, M. Adrian, D. Riek-Loher, B. Bohrmann, H. Dobeli, D. Schubert and R. Riek, Proc. Natl. Acad. Sci. U. S. A., 2005, 102, 17342-17347.

4 M. R. Sawaya, S. Sambashivan, R. Nelson, M. I. Ivanova, S. A. Sievers, M. I. Apostol, M. J. Thompson, M. Balbirnie, J. J. Wiltzius, H. T. McFarlane, A. O. Madsen, C. Riekel and D. Eisenberg, Nature, 2007, 447, 453-457.

5 L. Yu, R. Edalji, J. E. Harlan, T. F. Holzman, A. P. Lopez, B. Labkovsky, H. Hillen, S. Barghorn, U. Ebert, P. L. Richardson, L. Miesbauer, L. Solomon, D. Bartley, K. Walter, R. W. Johnson, P. J. Hajduk and E. T. Olejniczak, Biochemistry, 2009, 48, 1870-1877.

6 A. Laganowsky, C. Liu, M. R. Sawaya, J. P. Whitelegge, J. Park, M. Zhao, A. Pensalfini, A. B. Soriaga, M. Landau, P. K. Teng, D. Cascio, C. Glabe and D. Eisenberg, Science, 2012, 335, 1228-1231.

7 M. I. Apostol, K. Perry and W. K. Surewicz, J. Am. Chem. Soc., 2013, 135, 10202-10205.

8 O. Khakshoor, A. J. Lin, T. P. Korman, M. R. Sawaya, S. C. Tsai, D. Eisenberg and J. S. Nowick, J. Am. Chem. Soc., 2010, 132, 11622-11628.

9 C. Liu, M. R. Sawaya, P. N. Cheng, J. Zheng, J. S. Nowick and D. Eisenberg, J. Am. Chem. Soc., 2011, 133, 6736-6744.

10 P. N. Cheng, C. Liu, M. Zhao, D. Eisenberg and J. S. Nowick, Nat. Chem., 2012, 4, 927-933.

11 A. G. Kreutzer, I. L. Hamza, R. K. Spencer and J. S. Nowick, J. Am. Chem. Soc., 2016, 138, 4634-4642.

12 P. J. Salveson, R. K. Spencer and J. S. Nowick, J. Am. Chem. Soc., 2016, 138, 4458-4467. 
13 R. K. Spencer, A. G. Kreutzer, P. J. Salveson, H. Li and J. S. Nowick, J. Am. Chem. Soc., 2015, 137, 6304-6311.

14 C. Rapezzi, C. C. Quarta, L. Riva, S. Longhi, I. Gallelli, M. Lorenzini, P. Ciliberti, E. Biagini, F. Salvi and A. Branzi, Nat. Rev. Cardiol., 2010, 7, 398-408.

15 T. R. Foss, R. L. Wiseman and J. W. Kelly, Biochemistry, 2005, 44, 15525-15533.

16 K. Andersson, A. Olofsson, E. H. Nielsen, S.-E. Svehag and E. Lundgren, Biochem. Biophys. Res. Commun., 2002, 294, 309-314.

17 C. E. Bulawa, S. Connelly, M. Devit, L. Wang, C. Weigel, J. A. Fleming, J. Packman, E. T. Powers, R. L. Wiseman, T. R. Foss, I. A. Wilson, J. W. Kelly and R. Labaudiniere, Proc. Natl. Acad. Sci. U. S. A., 2012, 109, 9629-9634.

18 T. Klabunde, H. M. Petrassi, V. B. Oza, P. Raman, J. W. Kelly and J. C. Sacchettini, Nat. Struct. Biol., 2000, 7, 312-321.

19 A related cyclic peptide derived from the dimerization interface of the TTR tetramer has been found to inhibit A $\beta$ aggregation: P. Y. Cho, G. Joshi, M. D. Boersma, J. A. Johnson and R. M. Murphy, ACS Chem. Neurosci., 2015, 6, 778-789.

20 J. S. Nowick and J. O. Brower, J. Am. Chem. Soc., 2003, 125, 876-877.

$21 \beta$-Strand $\mathrm{G}$ of TTR (105-115) forms amyloid fibrils and binds A 8 : (a) J. A. Jarvis, D. A. Craik and M. C. J. Wilce, Biochem. Biophys. Res. Commun., 1993, 192, 991-998; (b) C. P. Jaroniec, C. E. MacPhee, N. S. Astrof, C. M. Dobson and R. G. Griffin, Proc. Natl. Acad. Sci. U. S. A., 2002, 99, 16748-16753; (c) D. T. Yang, G. Joshi, P. Y. Cho, J. A. Johnson and R. M. Murphy, Biochemistry, 2013, 52, 2849-2861.

22 If this ${ }^{\delta}$ Orn turn is omitted, the resulting acyclic peptide $(\mathrm{H}-$ Thr-Ile-Ala-N-Me-Ala-Leu-Leu-Ser- ${ }^{\delta}$ Orn-Ser-PheI-Ser-ThrThr-Ala-Val-OH) does not crystallize under the conditions that peptide $\mathbf{1}$ crystallizes. It also does not aggregate in thioflavin $\mathrm{T}$ fluorescence assays.

23 R. Spencer, K. H. Chen, G. Manuel and J. S. Nowick, Eur. J. Org. Chem., 2013, 3523-3528.

24 If the $N$-methyl group of peptide 1 is omitted, a gel forms when the cyclic peptide is deprotected. The placement of the $N$-methyl group on alanine 109 is important for crystallization; homologues with alternative placements of the $N$-methyl group do not crystallize under the conditions that peptide 1 crystallizes.

25 R. K. Spencer and J. S. Nowick, Isr. J. Chem., 2015, 55, 698710.

26 Thioflavin $\mathrm{T}$ fluorescence assays show that peptide 1 aggregates over the course of hours. Circular dichroism shows that the aggregates exhibit $\beta$-sheet structure. For details of these experiments, see the ESI. $\dagger$

27 J. D. Hartgerink, E. Beniash and S. I. Stupp, Science, 2001, 294, 1684-1688.

28 V. Jayawarna, M. Ali, T. A. Jowitt, A. F. Miller, A. Saiani, J. E. Gough and R. V. Ulijn, Adv. Mater., 2006, 18, 611-614.

29 R. J. Swanekamp, J. T. DiMaio, C. J. Bowerman and B. L. Nilsson, J. Am. Chem. Soc., 2012, 134, 5556-5559.

30 M. Reches and E. Gazit, Nat. Nanotechnol., 2006, 1, 195-200. 31 B. Sanii, R. Kudirka, A. Cho, N. Venkateswaran, G. K. Olivier, A. M. Olson, H. Tran, R. M. Harada, L. Tan and R. N. Zuckermann, J. Am. Chem. Soc., 2011, 133, 2080820815.

32 M. R. Ghadiri, J. R. Granja, R. A. Milligan, D. E. McRee and N. Khazanovich, Nature, 1993, 366, 324-327.

33 J. D. Hartgerink, J. R. Granja, R. A. Milligan and M. R. Ghadiri, J. Am. Chem. Soc., 1996, 118, 43-50.

34 K. Lu, J. Jacob, P. Thiyagarajan, V. P. Conticello and D. G. Lynn, J. Am. Chem. Soc., 2003, 125, 6391-6393.

35 A. K. Mehta, K. Lu, W. S. Childers, Y. Liang, S. N. Dublin, J. Dong, J. P. Snyder, S. V. Pingali, P. Thiyagarajan and D. G. Lynn, J. Am. Chem. Soc., 2008, 130, 9829-9835.

36 M. C. Branco, D. J. Pochan, N. J. Wagner and J. P. Schneider, Biomaterials, 2009, 30, 1339-1347.

37 J. E. Sun, B. Stewart, A. Litan, S. J. Lee, J. P. Schneider, S. A. Langhans and D. J. Pochan, Biomater. Sci., 2016, 4, 839-848.

38 S. Lindsey, J. H. Piatt, P. Worthington, C. Sonmez, S. Satheye, J. P. Schneider, D. J. Pochan and S. A. Langhans, Biomacromolecules, 2015, 16, 2672-2683.

39 P. N. Cheng, J. D. Pham and J. S. Nowick, J. Am. Chem. Soc., 2013, 135, 5477-5492. 